\title{
NOTCH and Graft-Versus-Host Disease
}

\author{
Mauro Di lanni, ${ }^{1,2 *}$, Beatrice Del Papa ${ }^{3+}$, Stefano Baldoni ${ }^{4}$, Ambra Di Tommaso4, \\ Bianca Fabi ${ }^{4}$, Emanuela Rosati ${ }^{5}$, Annalisa Natale², Stella Santarone ${ }^{2}$, Paola Olioso ${ }^{2}$, \\ Gabriele Papalinetti2 ${ }^{2}$ Raffaella Giancola², Patrizia Accorsi ${ }^{2}$, Paolo Di Bartolomeo², \\ Paolo Sportoletti ${ }^{3}$ and Franca Falzetti ${ }^{3}$
}

\begin{abstract}
'Department of Medicine and Aging Sciences, University of Chieti-Pescara, Chieti, Italy, ${ }^{2}$ Department of Hematology, Transfusion Medicine and Biotechnologies, Ospedale Civile, Pescara, Italy, ${ }^{3}$ Institute of Hematology-Centro di Ricerche Emato-Oncologiche (CREO), University of Perugia, Perugia, Italy, ${ }^{4}$ Department of Life, Health and Environmental Sciences, Hematology Section, University of L'Aquila, L'Aquila, Italy, ${ }^{5}$ Department of Experimental Medicine, Biosciences and Medical Embriology Section, University of Perugia, Perugia, Italy
\end{abstract}

\section{OPEN ACCESS}

Edited by:

Barbara A. Osborne,

University of Massachusetts

Amherst, United States

Reviewed by:

Ivan Maillard,

University of Pennsylvania,

United States

Stefanie Sarantopoulos,

Duke University, United States

Ronjon Chakraverty,

University College London,

United Kingdom

*Correspondence:

Mauro Di lann

mauro.diianni@unich.it

tThese authors have contributed equally to this work.

Specialty section: This article was submitted to Immunological Tolerance and Regulation,

a section of the journal

Frontiers in Immunology

Received: 30 March 2018

Accepted: 24 July 2018

Published: 10 August 2018

Citation:

Di lanni M, Del Papa B, Baldoni S, Di Tommaso A, Fabi B, Rosati E, Natale A, Santarone S, Olioso P, Papalinetti G, Giancola R, Accorsi $P$,

Di Bartolomeo P, Sportoletti P and

Falzetti $F$ (2018) NOTCH and

Graft-Versus-Host Disease.

Front. Immunol. 9:1825.

doi: 10.3389/fimmu.2018.01825
In allogeneic hematopoietic stem cell transplantation, which is the major curative therapy for hematological malignancies, T cells play a key role in the development of graftversus-host disease (GvHD). NOTCH pathway is a conserved signal transduction system that regulates $\mathrm{T}$ cell development and differentiation. The present review analyses the role of the NOTCH signaling as a new regulator of acute GvHD. NOTCH signaling could also represent a new therapeutic target for GvHD.

Keywords: NOTCH, graft-versus-host disease, tolerance, graft-versus-leukemia, HSCT

\section{INTRODUCTION}

Hematopoietic stem cell transplantation from allogeneic donors is the major curative therapy for hematological malignancies such as acute leukemias (ALs). The development of graft-versus-host disease (GvHD) is the most common complication which dramatically increases post-transplant morbidity and mortality (1). The clinical presentations of GvHD include acute GvHD (aGvHD) which regards $30-50 \%$ of transplanted patients and chronic GvHD (cGvHD) which includes $30-70 \%$ of patients who underwent allogeneic hematopoietic stem cell transplantation $(2,3)$. GvHD is triggered by the donor $\mathrm{T}$ cells that can cause an inflammatory disease ultimately leading to severe multiorgan damage (liver, gut, and skin) (4-8).

Donor $\mathrm{T}$ cells play a crucial role not only in mediating the onset of GvHD but also in eradicating malignancy, the graft-versus-leukemia $(\mathrm{GvL})$ effect as showed by clinical $(9,10)$ and experimental studies (11-13). Allogeneic T cells recognize host antigens on leukemic cells and leukemia-specific responses may also occur (14). Despite this strong GvL effect exerted by donor T cells, relapse is still the major cause of treatment failure in high-risk AL patients who underwent allogeneic HSCT (15-18). Strategies to separate GvHD and GvL are then under investigation.

The NOTCH signaling pathway relies on the interactions between receptors (NOTCH1-4) and ligands (Jagged 1 and -2 or Dll1, -3 , and -4) that are expressed on neighboring cells (19). The interactions NOTCH/NOTCH ligand induce proteolytic activation of the receptor by an ADAM family metalloprotease and then by the $\gamma$-secretase complex. The sequential cuts lead to the release of the active intracellular NOTCH (ICN) that enters the nucleus and interacts with the DNA binding CSL/ RBP-Jk factor, constituting a transcriptional activation complex with a mastermind-like (MAML) family coactivator. This ultimately promotes the transcription of target genes, controlling crucial biologic processes, such as survival, proliferation, and differentiation (20). Besides the canonical ICN/ CSL/MAML-dependent transcriptional activation, RBP-Jk-independent non-canonical NOTCH signaling have also described $(21,22)$. 
NOTCH signaling was first studied for its fundamental role in the early step of lymphopoiesis (23) and it has been implicated also in mature $\mathrm{T}$ cell function (24-26). More recently, NOTCH signaling has emerged as a new regulator of acute (27-32) and cGvHD (33). In this review, we will focus on NOTCH signaling and $\mathrm{aGvHD}$.

\section{NOTCH SIGNALING IS ACTIVATED DURING GvHD IN DONOR T CELLS}

$\mathrm{NOTCH}$ and alloimmune responses have been extensively studied in GvHD and in non-GvHd models. In Severe Aplastic Anemia (SAA) mouse model, Roderick et al. (34) showed NOTCH signaling mediate Th1 cell differentiation and T-BET expression. Treatment with $\gamma$-secretase inhibitors (GSIs) reduced NOTCH and T-BET expression and rescued mice from SAA.

In the setting of GvHD, the Kean group (35) demonstrated the existence of NOTCH-related signature in alloreactive T cells harvested from a non-human primate model.

The Maillard group reported that $\mathrm{NOTCH}$ signaling is a strong regulator of $\mathrm{T}$-cell activation, differentiation, and function during $\operatorname{GvHD}(28,36)$. Murine models of allo-HCT showed that inhibition of canonical NOTCH signaling markedly decreased GVHD severity and mortality (28-30). NOTCH inhibition dramatically reduced the accumulation of alloreactive $\mathrm{T}$ cells in the gut. Interestingly, NOTCH-inhibited $\mathrm{T}$ cells significantly retained their antileukemic activity. By using humanized antibodies and conditional genetic models, Tran et al. (29) demonstrated that all the effects of NOTCH signaling during GvHD were dependent on NOTCH1/2 receptors in $\mathrm{T}$ cells and Dll1/4 ligands in the recipient, with dominant roles for NOTCH1 and Dll4 (29). NOTCH-inhibited T cells acquire a hyporesponsive phenotype in both $\mathrm{CD} 4$ and $\mathrm{CD} 8$ populations. NOTCH deprived T cells markedly reduced cytokine production but maintain their expansion capacity and their in vitro cytotoxic ability (30).

The exact mechanisms of NOTCH modulation in T cells remain to be elucidated. Mochizuki et al. (37) in murine model showed that during GvHD, inflammatory DCs Dll4 ligand positive produce significantly high level of IFN- $\gamma$ and IL-17. More recently, Chung et al. (27) showed that NOTCH signal are delivered to donor $\mathrm{T}$ cells shortly after transplantation and that host stromal cells are the source for NOTCH ligands during in vivo priming of alloreactive T cells. Interestingly, Luo et al. (38) have shown in an MHC-mismatched murine all-BMT model, inhibition of $\mathrm{NOTCH}$ signaling reduce the incidence of GvHD by reducing DCs and CD8 T cell proliferation and activation.

NOTCH pathway inhibition could be therapeutically targeted by: (1) GSIs that block the proteolytic activation after the $\mathrm{NOTCH} / \mathrm{NOTCH}$ ligand interaction (39). However, the use of GSIs in murine model of GvHD is associated with a severe toxicity in the gut epithelium (29); (2) monoclonal antibodies directed against NOTCH ligands such as Dll1-4 (29); (3) we recently identified the calcium channel modulator bepridil as a new NOTCH1 pathway inhibitor in Chronic Lymphocytic Leukemia (40). It represents an attractive therapeutic strategy to prevent also GvHD (Figure 1).

\section{REGULATORY T CELLS (Tregs) DOWNREGULATE NOTCH SIGNALING IN DONOR T CELLS}

Regulatory $\mathrm{T}$ cells suppressed alloimmune reactions like, for example, GvHD (41). They also promoted tolerance to allogeneic organ transplants (42). Adoptive Treg/conventional T cell (Tcons)-based immunotherapy in full-haplotype mismatched transplantation practically eliminated acute and cGvHD, supported post-transplant immunological reconstitution and exerted a strong GvL effect (43-48) in high-risk AL patients.

Although the mechanisms underlying Treg suppression of GvHD with no loss of GvL activity remain to be unraveled, the principal hypotheses are based on (a) the Treg/Tcon homing and distribution patterns and (b) different molecular pathways in Tcon activation and proliferation and, consequently, GvL and GvHD. Interestingly, using humanized antibodies and conditional genetic mouse models to inactivate NOTCH signaling in donor T cells markedly reduced GvHD severity and mortality (28-30). NOTCH signaling other than a cell autonomous mechanism can be modulated with an extrinsic signal from an adjacent interacting cell. Current evidence suggests that Tregs and anti-NOTCH1 compounds inhibit the same NOTCH ligands and receptors on Tcons $(29,49)$. Mimicking the drug-mediated NOTCH1 inhibition (30), Tregs directly inhibited NOTCH1 signaling on Tcons in vitro and in vivo, with the blockade being observed on CD4 and CD8 cells from mouse lymph nodes (49). Jagged 1 and Dll4 NOTCH1 ligands, played major roles (49) with Dll4 being reported to mediate all NOTCH signaling effects in Tcons during GvHD (29). As a GvHD prevention strategy, using alloantigen-specific Tregs which preferentially inhibit alloreactive Tcons to downregulate NOTCH1 clearly offers advantages over administering pharmaceutical agents which exert a total blockade on NOTCH1 signaling on all Tcons.

CD39-NOTCH1 pathway crosstalk was also demonstrated (49). In fact, NOTCH1 expression and signaling on Tcons were restored when CD39 was blocked by the anti-CD39 monoclonal antibody or polyoxometalate-1 (POM-1), the selective CD39 inhibitor (49). Increased cAMP levels were associated with NOTCH1 reduction in Tcons; adding anti-CD39 reduced cAMP levels and reversed the Treg-mediated NOTCH1 reduction. GvHD reappeared in mice after POM-1 administration (49). In vitro studies (50-52) showed that blocking Abs or chemical products downmodulated the CD39/adenosine axis and reversed Treg suppression of $\mathrm{T}$ cons. Although the Treg mechanisms of action are multiple and partially unclear (53), these data showed that Tregs triggered NOTCH1 downregulation directly in Tcons and acted through the CD39/adenosine axis to inhibit the NOTCH pathway which, in turn, regulates Tcon proliferation (Figure 1). This mechanism of action could account for Treg-induced inhibition of Tcon proliferation which was observed by others (30).

Interestingly, in CD4 and CD8 cell populations, NOTCH1 downregulation was more marked in peripheral blood than in bone marrow (54). Tregs were demonstrated to block Tcons in the periphery but not in bone marrow (55). We could speculate that Treg homing patterns play a major role in these results. Tregs could have downregulated NOTCH1 expression in peripheral 


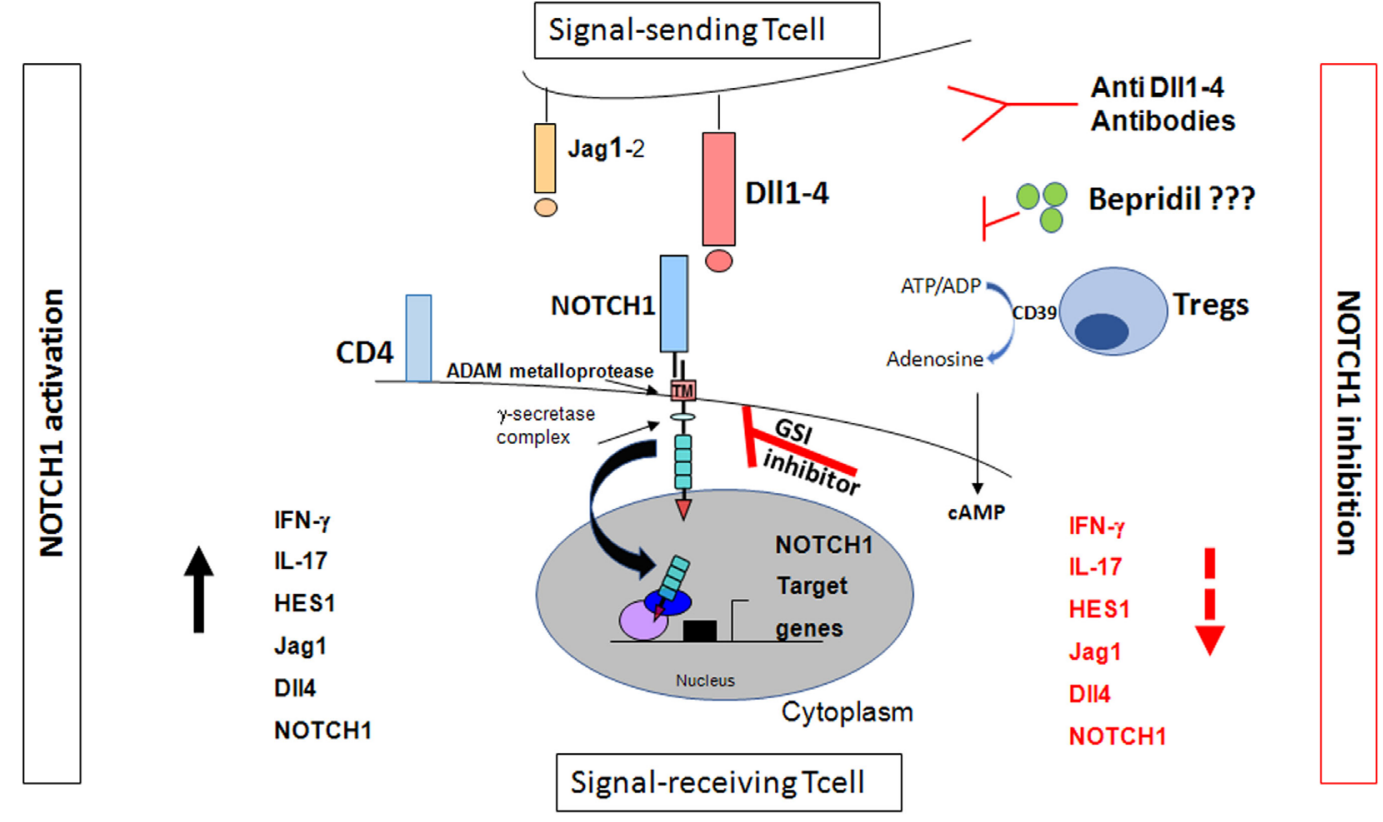

\section{GvHD onset}

\section{GvHD inhibition}

FIGURE 1 | NOTCH signaling and graft-versus-host disease (GvHD). The effects of NOTCH signaling during GvHD are dependent on NOTCH1/2 receptors in T cells and DIl1/4 ligands in the recipient, with dominant roles for NOTCH1 and D\|l4. Inhibition of canonical NOTCH signaling by $\gamma$-secretase inhibitor (GSI)-inhibitor, anti DIl1-4 antibodies, bepridil, and regulatory T cells (Tregs) markedly decreased GVHD (28-30). Tregs inhibit the NOTCH/NOTCH ligand interactions. They act through the CD39/adenosine axis to inhibit the NOTCH pathway which, in turn, regulates T cell proliferation and consequently inhibits GvHD. Blocking CD39/ adenosine axis reverts NOTCH inhibition and favors GvHD onset (49).

tissue because they homed there while, because of different migratory properties, they homed less efficiently, or not at all, to bone marrow. Translation of tissue-specific NOTCH1 expression into a strong GvL effect without GvHD, needs, however, to be elucidated in depth. A Treg-related NOTCH1 blockade could account for clinical and experimental evidence that Tregs prevented GvHD and facilitated a powerful Tcon-dependent GvL effect $(44,45)$. Consequently Treg-mediated NOTCH inhibition, like drug-induced NOTCH downregulation (28-30) may separate GvHD from GvL. This finding has major implications for adoptive immunotherapy strategies in the field of transplantation for leukemia.

\section{MESENCHYMAL STEM CELLS (MSCs) RECRUIT INDUCED Tregs (iTregs) BY ACTIVATING NOTCH SIGNALING}

NOTCH1 signaling is also involved in Treg cell differentiation. Liotta et al. had described Jagged1 involvement in MSC suppression of T-cell proliferation (56). Our group showed when cocultured with CD3+ cells, MSCs induced a T-cell population with a regulatory phenotype (57). When CD4+ $\mathrm{T}$ cells were cocultured with MSCs, the NOTCH1 pathway was found to be activated (58). Using GSI-I or the NOTCH1 neutralizing antibody to inhibit NOTCH1 signaling reduced HES1 expression (the NOTCH1 downstream target) and the percentage of MSCinduced CD4+CD25highFOXP3+ cells in vitro (58) (Figure 2). In human cells FOXP3 is another NOTCH signaling downstream target (58), thus data from murine models were extended (59). NOTCH signaling activation reversed the unstable regulatory/ suppressive properties of iTreg cells, ensuring sustained FOXP3 expression and stable Treg-cell phenotypes (58). No crosstalk between NOTCH1 and TGF- $\beta$ signaling pathways was observed (58). Previous studies had demonstrated TGF- $\beta$ production was involved in MSCs-mediated Treg cell induction $(60,61)$ and reported TGF- $\beta / \mathrm{NOTCH} 1$ crosstalk (58) in peripheral Treg cell maintenance. Lack of T-cell receptor stimulation in the work by Del Papa et al. may account for the discrepancy with other reports (58, 62-64). Together, these findings indicated that NOTCH1 pathway activation played a role in MSC-mediated human Tregcell induction. In conclusion while on one side our observation on MSC-T cell coculture suggest a positive role of NOTCH in the generation of iTregs, on the other side $\mathrm{NOTCH}$ inhibition (drug or Treg mediated) in mature donor T cells is associated with reduction in GvHD severity and mortality. 


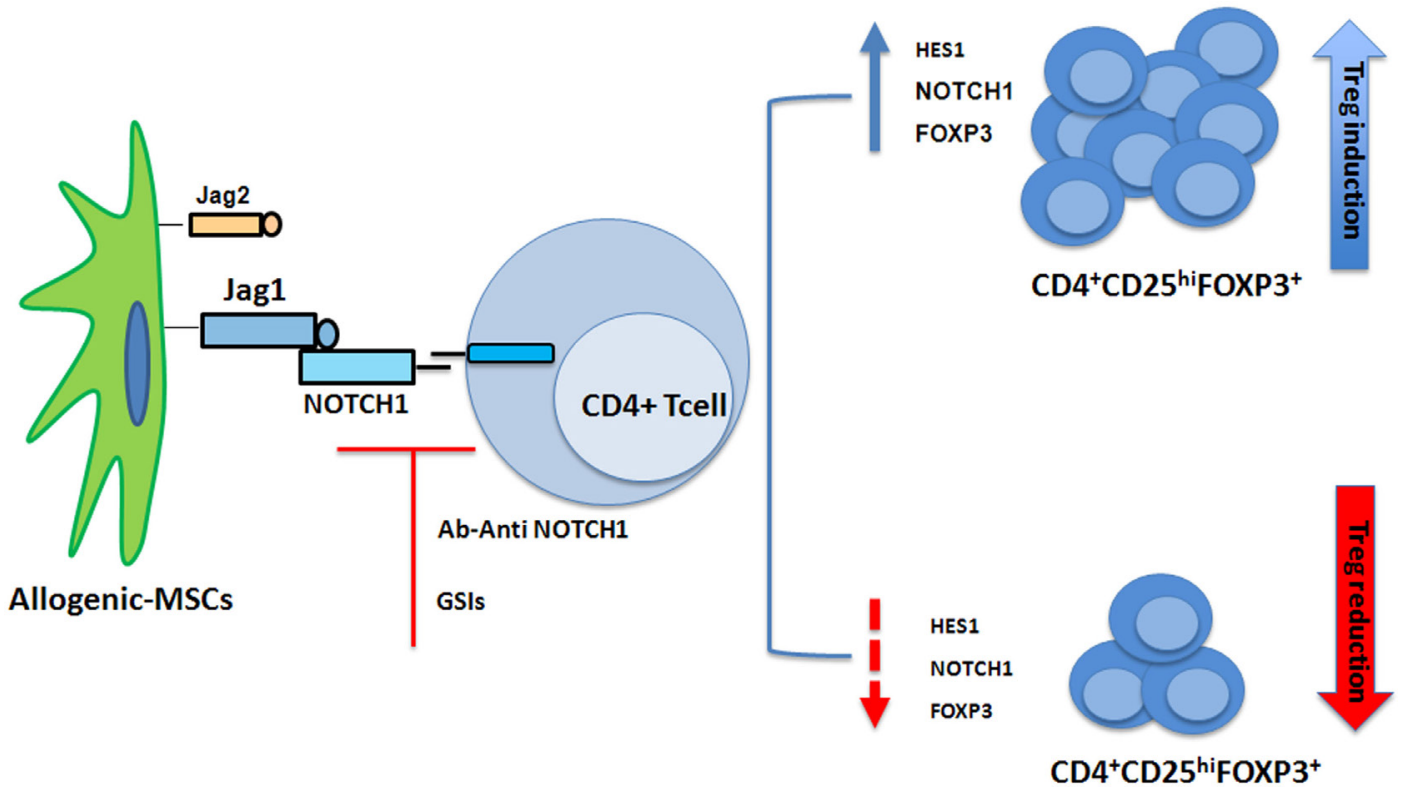

FIGURE 2 | Mesenchymal stem cells (MSCs) recruit induced Tregs (iTregs) by activating Notch signaling. When cocultured with CD4+ cells, MSCs induced a T-cell population with a regulatory phenotype (iTregs) (57). NOTCH1 pathway is activated in CD4+ T cells cocultured with MSCs. Inhibition of NOTCH1 signaling through $\gamma$-secretase inhibitor (GSI)-I or the NOTCH1 neutralizing antibody reduced expression of HES1 and the percentage of MSC-induced CD4+CD25highFOXP3+ cells in vitro (58).

\section{CONCLUSION AND PERSPECTIVES}

Allogeneic immune system played a crucial role not only in mediating the onset of GvHD but also in eradicating malignancy, i.e., the GvL effect. Separating GvHD from GvL represent a major challenge. GvHD prophylaxis and treatment is mainly based on immunosuppressive treatment with drugs such as cyclosporine, tacrolimus, methotrexate, antithymocyte globulin, and glucocorticoids (4). Data reviewed here showed NOTCH1 as a new

\section{REFERENCES}

1. Blazar BR, Murphy WJ, Abedi M. Advances in graft-versus-host disease biology and therapy. Nat Rev Immunol (2012) 12(6):443-58. doi:10.1038/ nri3212

2. Wingard JR, Majhail NS, Brazauskas R, Wang Z, Sobocinski KA, Jacobsohn D, et al. Long-term survival and late deaths after allogeneic stem cell transplantation. J Clin Oncol (2011) 29(16):2230-9. doi:10.1200/JCO.2010.33.7212

3. Pidala J, Anasetti C. Glucorticoid-refractory acute graft-versus-host disease. Biol Blood Marrow Transplant (2011) 16(11):1504-18. doi:10.1016/j. bbmt.2010.01.007

4. Zeiser R, Blazar BR. Acute graft-versus-host disease-biologic process, prevention, and therapy. N Engl J Med (2017) 377(22):2167-79. doi:10.1056/ NEJMra1609337

5. Ghimire S, Weber D, Mavin E, Wang XN, Dickinson AM, Holler E. Pathophysiology of GvHD and other HSCT-related major complications. Front Immunol (2017) 8:79. doi:10.3389/fimmu.2017.00079

6. Coghill JM, Sarantopoulos S, Moran TP, Murphy WJ, Blazar BR, Serody JS. Effector CD4+ T cells, the cytokines they generate, and GVHD: something old and something new. Blood (2011) 117(12):3268-76. doi:10.1182/blood2010-12-290403

7. Zeiser R, Blazar BR. Pathophysiology of chronic graft-versus-host disease and therapeutic targets. N Engl J Med (2017) 377(26):2565-79. doi:10.1056/ NEJMra1703472 major regulator of alloreactivity. Triggering NOTCH pathway with pharmacological (GSIs, Ab anti-Notch) or cellular (Tregs) ways might represent a new strategy to separate GvHD from GvL.

\section{AUTHOR CONTRIBUTIONS}

MDI organized the plan and structure of the manuscript, and all the authors contributed to the redaction.

8. Wolff D, Gerbitz A, Ayuk F, Kiani A, Hildebrandt GC, Vogelsang GB, et al Consensus conference on clinical practice in chronic graft-versus-host disease (GVHD): first-line and topical treatment of chronic GVHD. Biol Blood Marrow Transplant (2010) 16(12):1611-28. doi:10.1016/j.bbmt.2010. 06.015

9. Weiden PL, Flournoy N, Thomas ED, Prenticee R, Fefer A, Buckner CD, et al. Antileukemic effect of graft-versus-host disease in human recipients of allogeneic marrow grafts. N Engl J Med (1979) 300:1068-10739. doi:10.1056/ NEJM197905103001902

10. Horowitz MM, Gale RP, Sondel PM, Goldman JM, Kersey J, Kolb HJ, et al. Graft versus leukemia reactions after bone marrow transplantation. Blood (1990) 75(3):555-62.

11. Kloosterman TC, Martens AC, van Bekkum DW, Hagenbeek A. Graft-versusleukemia in rat $\mathrm{MHC}$-mismatched bone marrow transplantation is merely an allogeneic effect. Bone Marrow Transplant (1995) 15(4):583-90.

12. Bortin MM, Truitt RL, Rimm AA, Bach FH. Graft-versus-leukaemia reactivity induced by alloimmunisation without augmentation of graft-versus-host reactivity. Nature (1979) 281(5731):490-1. doi:10.1038/281490a0

13. Reddy P, Maeda Y, Liu C, Krijanovski OL, Korngold R, Ferrara JL. A crucial role for antigen-presenting cells and alloantigen expression in graft-versusleukemia responses. Nat Med (2005) 11(11):1244-9. doi:10.1038/nm1309

14. Rezvani K, Barrett AJ. Characterizing and optimizing immune response to leukaemia antigens after allogeneic stem cell transplantation. Best Pract Res Clin Hematol (2008) 21(3):437-53. doi:10.1016/j.beha.2008.07.004 
15. Gupta V, Tallman MS, He W, Logan BR, Copelan E, Galeet RP, et al. Comparable survival after HLA-well-matched unrelated or matched sibling donor transplantation for acute myeloid leukemia in first remission with unfavorable cytogenetics at diagnosis. Blood (2010) 116(11):1839-48. doi:10.1182/ blood-2010-04-278317

16. Bashey A, Zhang X, Sizemore C, Manion K, Brown S, Holland HK, et al. $\mathrm{T}$ cell replete HLA-haploidentical hematopoietic transplantation for hematologic malignancies using post-transplantation cyclophosphamide. Results in outcomes equivalent to those of contemporaneous HLA-matched related and unrelated donor transplantation. J Clin Oncol (2013) 31(10):1310-6. doi:10.1200/JCO.2012.44.3523

17. Scaradavou A, Brunstein CG, Eapen M, Le-Rademacher J, Barker JN, Chao N, et al. Double unit grafts successfully extend the application of umbilical cord blood transplantation in adults with acute leukemia. Blood (2013) 121:752-8. doi:10.1182/blood-2012-08-449108

18. Di Bartolomeo P, Santarone S, De Angelis G, Picardi A, Cudillo A, Cerretti R, et al. Haploidentical unmanipulated, G-CSF-primed bone marrow transplantation for patients with high risk hematological malignancies. Blood (2013) 121(5):849-57. doi:10.1182/blood-2012-08-453399

19. Hori K, Sen A, Artavanis-Tsakonas S. Notch signaling at a glance. J Cell Sci (2013) 126(Pt10):2135-40. doi:10.1242/jcs.127308

20. Grazioli P, Felli MP, Screpanti I, Campese AF. The mazy case of Notch and immunoregulatory cells. J Leukoc Biol (2017) 102(2):361-8. doi:10.1189/ jlb.1VMR1216-505R

21. Toubai T, Tawara I, Sun Y, Liu C, Nieves E, Evers R, et al. Induction of acute GVHD by sex-mismatched H-Y antigens in the absence of functional radiosensitive host hematopoietic-derived antigen-presenting cells. Blood (2012) 119(16):3844-53. doi:10.1182/blood-2011-10-384057

22. Li H, Demetris AJ, McNiff J, Matte-Martone C, Tan HS, Rothstein DM, et al. Profound depletion of host conventional dendritic cells, plasmacytoid dendritic cells, and B cells does not prevent graft-versus-host disease induction. J Immunol (2012) 188(8):3804-11. doi:10.4049/jimmunol.1102795

23. Radtke F, Fasnacht N, MacDonald HR. Notch signaling in the immune system. Immunity (2010) 32:14-27. doi:10.1016/j.immuni.2010.01.004

24. Osborne BA, Minter LM. Notch signalling during peripheral T-cell activation and differentiation. Nat Rev Immunol (2007) 7:64-75. doi:10.1038/nri1998

25. Amsen D, Antov A, Flavell RA. The different faces of Notch in t-helper differentiation. Nat Rev Immunol (2009) 9:116-24. doi:10.1038/nri2488

26. Backer RA, Helbig C, Gentek R, Kent A, Laidlaw BJ, Dominguez CX, et al. A central role for Notch in effector CD8+ T cell differentiation. Nat Immunol (2014) 15:1143-51. doi:10.1038/ni.3027

27. Chung J, Ebens CL, Perkey E, Radojcic V, Koch U, Scarpellino L, et al. Fibroblasic niche prime T cell alloimmunity through delta-like Notch ligands. J Clin Invest (2017) 127(4):1574-88. doi:10.1172/JCI89535

28. Zhang Y, Sandy AR, Wang J, Radojcic V, Shan GT, Tran IT, et al. Notch signaling is a critical regulator of allogeneic CD4+ T-cell responses mediating graft-versus-host disease. Blood (2011) 117(1):299-308. doi:10.1182/ blood-2010-03-271940

29. Tran IT, Sandy AR, Carulli AJ, Ebens C, Chung J, Shan GT, et al. Blockade of individual Notch ligands and receptors controls graft-versus-host disease. J Clin Invest (2013) 123(4):1590-604. doi:10.1172/JCI65477

30. Sandy AR, Chung J, Toubai T, Shan GT, Tran YT, Friedman A, et al. T cell-specific Notch inhibition blocks graft-versus-host disease by inducing a hyporesponsive program in alloreactive CD\$+ and CD8+ T cells. J Immunol (2013) 190(11):5818-28. doi:10.4049/jimmunol.1203452

31. Charbonnier LM, Wang S, Georgiev P, Sefik E, Chatila TA. Control of peripheral tolerance by regulatory $\mathrm{T}$ cell-intrinsic Notch signaling. Nat Immunol (2015) 16(11):1162-73. doi:10.1038/ni.3288

32. Santos e Sousa P, Cirè S, Conlan T, Jardine L, Tkacz C, Ferrer IR, et al. Peripheral tissues reprogram CD8+ T cells for pathogenicity during graft-versus-host disease. JCI Insight (2018) 3(5):e97011. doi:10.1172/jci.insight.97011

33. Poe JC, Jia W, Su H, Anand S, Rose JJ, Tata PV, et al. An aberrant NOTCH2BCR signaling axis in B cells from patients with chronic GvHD. Blood (2017) 130:2131-45. doi:10.1182/blood-2017-05-782466

34. Roderick JE, Gozalez-Perez G, Kuksin CA, Dongre A, Roberts ER, Srinivasan J, et al. Therapeutic targeting of NOTCH signaling ameliorates immune-mediated bone marrow failure of aplastic anemia. J Exp Med (2013) 210:1311-29. doi:10.1084/jem.20112615
35. Furlan SN, Watkins B, Tkachev V, Flynn R, Cooley S, Ramakrishnan S, et al. Trascriptome analysis of GvHD reveals aurora kinase A as a targetable pathway for disease prevention. Sci Transl Med (2016) 7:315ra191. doi:10.1126/ scitranslmed.aad3231

36. Perkey E, Maillard I. New insights into graft-versus-host disease and graft rejection. Annu Rev Pathol (2018) 13:219-45. doi:10.1146/annurev-pathol020117-043720

37. Mochizuki K, Xie F, He S, Tong Q, Liu Y, Mochizuki I, et al. Delta-like ligand 4 identifies a previously uncharacterized population of inflammatory dendritic cells that plays important roles in eliciting allogeneic $\mathrm{T}$ cell responses in mice. J Immunol (2013) 190:3772-82. doi:10.4049/jimmunol.1202820

38. Luo X, Xu L, Li Y, Tan H. Notch pathway plays a novel and critical role in regulating responses of $\mathrm{T}$ and antigen presenting cells in GvHD. Cell Biol Toxicol (2017) 33:169-81. doi:10.1007/s10565-016-9364-7

39. Wolfe MS. $\gamma$-secretase in biology and medicine. Semin Cell Dev Biol (2009) 20:219-24. doi:10.1016/j.semcdb.2008.12.011

40. Baldoni S, Del Papa B, Dorillo E, Aureli P, De Falco F, Rompietti C, et al. Bepridil exhibits anti-leukemic activity associated with NOTCH1 pathway inhibition in chronic lymphocytic leukemia. Int J Cancer (2018) 143(4):958-70. doi:10.1002/ijc.31355

41. Edinger M, Hoffmann P, Ermann J, Drago K, Fathman CG, Strober S, et al. CD4+CD25+ regulatory $\mathrm{T}$ cells preserve graft-versus-tumor activity while inhibiting graft-versus-host disease after bone marrow transplantation. Nat Med (2003) 9:1144-50. doi:10.1038/nm915

42. Sakaguchi $\mathrm{S}$. Naturally arising CD4+ regulatory $\mathrm{T}$ cells for immunologic self-tolerance and negative control of immune responses. Annu Rev Immunol (2004) 22:531-62. doi:10.1146/annurev.immunol.21.120601.141122

43. Di Ianni M, Del Papa B, Zei T, Iacucci Ostini R, Cecchini D, Cantelmi MG, et al. T regulatory cell separation for clinical application. Transfus Apher Sci (2012) 47(2):213-6. doi:10.1016/j.transci.2012.06.007

44. Di Ianni M, Falzetti F, Carotti A, Terenzi A, Castellino F, Bonifacio E, et al. Tregs prevent GVHD and promote immune reconstitution in HLAhaploidentical transplantation. Blood (2011) 117(14):3921-8. doi:10.1182/ blood-2010-10-311894

45. Martelli MF, Di Ianni M, Ruggeri L, Falzetti F, Carotti A, Terenzi A, et al. HLA-haploidentical transplantation with regulatory and conventional $\mathrm{T}$ cell adoptive immunotherapy prevents acute leukemia relapse. Blood (2014) 124(4):638-44. doi:10.1182/blood-2014-03-564401

46. Martelli MF, Di Ianni M, Ruggeri L, Pierini A, Falzetti F, Carotti A, et al. "Designed" grafts for HLA-haploidentical stem cell transplantation. Blood (2014) 123:967-73. doi:10.1182/blood-2013-10-531764

47. Lussana F, Di Ianni M, Rambaldi A. Tregs: hype or hope for allogeneic hematopoietic stem cell transplantation? Bone Marrow Transplant (2017) 52:1225-32. doi:10.1038/bmt.2017.30

48. Del Papa B, Ruggeri L, Urbani E, Baldoni S, Cecchini D, Zei T, et al. Clinicalgrade-expanded regulatory $\mathrm{T}$ cells prevent graft-versus-host disease while allowing a powerful $\mathrm{T}$ cell dependent graft-versus-leukemia effect in murine models. Biol Blood Marrow Transplant (2017) 23(11):1847-51. doi:10.1016/j. bbmt.2017.07.009

49. Del Papa B, Pierini A, Sportoletti P, Baldoni S, Cecchini D, Rosati E, et al. The NOTCH1/CD39 axis: a Treg trip-switch for GvHD. Leukemia (2016) 30(9):1931-4. doi:10.1038/leu.2016.87

50. Nikolova M, Carriere M, Jenabian MA, Limou S, Younas M, Kok A, et al. CD39/adenosine pathway is involved in AIDS progression. PLoS Pathog (2011) 7:e1002110. doi:10.1371/journal.ppat.1002110

51. Schuler PJ, Harasymczuk M, Schilling B, Lang S, Whiteside TL. Separation of human CD4+CD39+ T cells by magnetic beads reveals two phenotypically and functionally different subsets. J Immunol Methods (2011) 369(1-2):59-68. doi:10.1016/j.jim.2011.04.004

52. Sun X, Wu Y, Gao W, Enjyoji K, Csizmadia E, Muller CE, et al. CD39/ENTPD1 expression by CD4+FoxP3+ regulatory $\mathrm{T}$ cells promotes hepatic metastatic tumor growth in mice. Gastroenterology (2010) 139(3):1030-40. doi:10.1053/j. gastro.2010.05.007

53. Caridade M, Graca L, Ribeiro RM. Mechanisms underlying CD4+ Treg immune regulation in the adult: from experiments to models. Front Immunol (2013) 18(4):378. doi:10.3389/fimmu.2013.00378

54. Di Ianni M, Olioso P, Giancola R, Santarone S, Natale A, Papalinetti G, et al. Treg-protected donor lymphocyte infusions: a new tool to address the 
graft-versus-leukemia effect in the absence of graft-versus-host disease in patients relapsed after HSCT. Int J Hematol (2017) 106(6):860-4. doi:10.1007/ s12185-017-2292-3

55. Ruggeri L, Di Ianni M, Urbani E, Mancusi A, Falzetti F, Carotti A, et al. Tregs suppress GvHD at the periphery and unleash the Gvl effect in the bone marrow. Blood (2014) 124(21):842.

56. Liotta F, Angeli R, Cosmi L, Filì L, Manuelli C, Frosali F, et al. Toll-like receptors 3 and 4 are expressed by human bone marrow-derived mesenchymal stem cells and can inhibit their T-cell modulatory activity by impairing Notch signaling. Stem Cells (2008) 26(1):279-89. doi:10.1634/stemcells.2007-0454

57. Di Ianni M, Del Papa B, De Ioanni M, Moretti L, Bonifacio E, Cecchini D, et al. Mesenchymal cells recruit and regulate T regulatory cells. Exp Hematol (2008) 36(3):309-18. doi:10.1016/j.exphem.2007.11.007

58. Del Papa B, Sportoletti P, Cecchini D, Rosati E, Balucani C, Baldoni S, et al. Notch1 modulates MSC-mediated regulatory T cell induction. Eur J Immunol (2013) 43(1):182-7. doi:10.1002/eji.201242643

59. Samon JB, Champhekar A, Minter LM, Telfer JC, Miele L, Fauq A, et al. Notch1 and TGFbetal cooperatively regulate Foxp3 expression and the maintenance of peripheral regulatory T cells. Blood (2008) 112(5):1813-21. doi:10.1182/ blood-2008-03-144980

60. English K, Ryan JM, Tobin L, Murphy MJ, Barry FP, Mahon BP. Cell contact, prostaglandin $\mathrm{E}(2)$ and transforming growth factor beta 1 play non-redundant roles in human mesenchymal stem cell induction of CD4+CD25(High) forkhead box P3+ regulatory T cells. Clin Exp Immunol (2009) 156(1):149-60. doi:10.1111/j.1365-2249.2009.03874.x

61. Chen W, Jin W, Hardegen N, Lei KJ, Li L, Marinos N, et al. Conversion of peripheral $\mathrm{CD} 4+\mathrm{CD} 25$ - naive $\mathrm{T}$ cells to $\mathrm{CD} 4+\mathrm{CD} 25+$ regulatory $\mathrm{T}$ cells by TGF-beta induction of transcription factor Foxp3. J Exp Med (2003) 198(12):1875-86. doi:10.1084/jem.20030152

62. Yamagiwa S, Gray JD, Hashimoto S, Horwitz DA. A role for TGF-beta in the generation and expansion of $\mathrm{CD} 4+\mathrm{CD} 25+$ regulatory $\mathrm{T}$ cells from human peripheral blood. J Immunol (2001) 166(12):7282-9. doi:10.4049/ jimmunol.166.12.7282

63. Fantini MC, Becker C, Monteleone G, Pallone F, Galle PR, Neurath MF. Cutting edge: TGFbeta induces a regulatory phenotype in CD4+CD25- T cells through Foxp3 induction and downregulation of Smad7. J Immunol (2004) 172(9):5149-53. doi:10.4049/jimmunol.172.9.5149

64. Kretschmer K, Apostolou I, Hawiger D, Khazaie K, Nussenzweig MC, von Boehmer $\mathrm{H}$. Inducing and expanding regulatory $\mathrm{T}$ cell populations by foreign antigen. Nat Immunol (2005) 6(12):1219-27. doi:10.1038/ni1265

Conflict of Interest Statement: The authors declare that the research was conducted in the absence of any commercial or financial relationships that could be construed as a potential conflict of interest.

Copyright (c) 2018 Di Ianni, Del Papa, Baldoni, Di Tommaso, Fabi, Rosati, Natale, Santarone, Olioso, Papalinetti, Giancola, Accorsi, Di Bartolomeo, Sportoletti and Falzetti. This is an open-access article distributed under the terms of the Creative Commons Attribution License (CC BY). The use, distribution or reproduction in other forums is permitted, provided the original author(s) and the copyright owner(s) are credited and that the original publication in this journal is cited, in accordance with accepted academic practice. No use, distribution or reproduction is permitted which does not comply with these terms. 